\title{
Corpus
}

Archivos virtuales de la alteridad americana

Vol. 11, No. 1 | 2021

Enero / Junio de 2021

\section{Baquedano y el muro. Patrimonio blindado y lugares de memoria}

Javiera Bustamante Danilo

\section{OpenEdition}

1 Journals

\section{Electronic version}

URL: https://journals.openedition.org/corpusarchivos/4575

DOI: 10.4000/corpusarchivos. 4575

ISSN: 1853-8037

\section{Publisher}

Diego Escolar

\section{Electronic reference}

Javiera Bustamante Danilo, «Baquedano y el muro. Patrimonio blindado y lugares de memoria», Corpus [En línea], Vol. 11, №. 1 | 2021, Publicado el 29 junio 2021, consultado el 03 julio 2021. URL: http://journals.openedition.org/corpusarchivos/4575; DOI: https://doi.org/10.4000/corpusarchivos 4575

This text was automatically generated on 3 July 2021. 


\title{
Baquedano y el muro. Patrimonio blindado y lugares de memoria
}

\author{
Javiera Bustamante Danilo
}

\author{
¿Viste el contingente de pacos que están \\ cuidando al Baquedano en Plaza Italia? Sí, no se \\ pa' que lo protegen tanto, si es un pedazo de \\ piedra, cuando se necesita tanto la policía en \\ otros lados... Podrían llevarse al Baquedano a \\ Puente Alto, así tendríamos a la policía ahí pa' \\ cuidarnos de tanta delincuencia. Relato de \\ feriantes en una feria de Santiago. Enero de 2021
}

(Bustamante 2021).

1 En el mes de noviembre de 2012, tiempo antes de que el monumento al general Baquedano se convirtiera en objeto de batalla, el italiano experto en patrimonio Salvatore Settis exponía en el Festival Puerto de las Ideas en la ciudad de Valparaíso sobre la crisis que vivía el patrimonio a nivel global. Sus palabras brindaban la visión de que el mundo, desde hace al menos dos décadas, comenzaba a tomar conciencia que debíamos superar la idea canónica del patrimonio como mero paisaje, neutro y prístino, y que debíamos hacernos cargo de su intrínseco carácter dinámico y disonante. En uno de los pasajes de su presentación, Settis evocó el principio dual del patrimonio; esto es que es un bien público, en el sentido de lo público sobre lo privado, pero al mismo tiempo, nos advierte, éste se cultiva en la acción popular y que ahí radicaría precisamente el giro crítico desde una visión canónica y tradicional a una más actualizada. En efecto, y a lo largo de los años, el monumento a Baquedano ha sido testigo de una constante ocupación cultural, social y deportiva, epicentro popular de las celebraciones y festividades que periódicamente lo habitaban y apropiaban y que no obstante los disturbios, intervenciones gráficas e intentos de resignificación al héroe patrio, sobrevivía en una tensión casi inofensiva, como nos advierte Jonhatan Lukinovic; "en lo cotidiano, estos monumentos parecieran integrase inocentemente en su entorno, formando parte del día a día de las personas” (2021, p.7). 
2 ¿En qué momento el monumento a Baquedano traspasa esa fuerza dada por la acción popular y se convierte en campo de batalla entre la sociedad civil, el cenáculo de profesionales y técnicos del patrimonio y el Estado? ¿Qué fuerzas ensalzan la obsesión por su protección y restauración y que llevan finalmente a renunciar a permanecer en su lugar de origen? En su obra de los lugares de la memoria, el francés Pierre Nora nos advierte que la memoria es sospechosa de la historia; la memoria instala el recuerdo en lo sagrado, mientras que la historia prosifica. Pero los lugares de la memoria fijan para la posteridad pasajes de nuestra historia; ahí en su materialidad más pétrea y reluciente cumple el cometido de representar aquellas épicas que el paso del tiempo amenaza con olvidar y desaparecer. Así, se espera que los monumentos asuman en forma ejemplar el linaje comunitario que nos une como nación, y para ello, no hay mayor atributo que defender la sobrevivencia material del monumento en el espacio público, encargados de recordarnos, tal como lo hace el monumento a Baquedano, que nuestra historia pasada está cargada de actos heroicos de valentía, fuerza patriótica y resistencia; Baquedano monumento como un lugar de la memoria nacional y de las épicas militares que no pueden ni deben ser olvidadas por la sociedad, como si fuese "lo más parecido a un combustible de reserva que puede ser utilizado en momentos de debilidad moral, que revitaliza el organismo dormido y lo salva de la melancolía y la muerte" (Chababo, 2017, p.33). En contraposición, la férrea resistencia a la erosión material del monumento, a su desfiguración y deformación física, es la resistencia a aceptar, públicamente, el lado más oscuro e ignominioso de nuestra historia, el de la experiencia colonizadora y represiva encarnada en la integridad de ese monumento, como si la transmisión efectiva y afectiva del relato histórico y de esa memoria estuviese amarrada a la sobrevivencia material, desconsiderando que para que ese vínculo sea posible, se debe dejar abierta la posibilidad de reelaborar el relato de acuerdo a los propios sentidos de identificación y significación.

3 La erosión material, y también simbólica- de Baquedano, nos recuerda así la acción conocida como damnatio memoriae (en locución latina se traduce literalmente como la condena de la memoria), una práctica de condena recurrente de la Antigua Roma que no buscaba otra cosa que condenar el recuerdo del enemigo tras su muerte, eliminando por parte de los vencedores todo cuanto recordara al condenado: imágenes, monumentos, inscripciones. En efecto, en el centro de nuestra capital, en la renombrada Plaza Dignidad, durante meses la protesta social, ahora desde la subalternidad, ha condenado la memoria oficial que encarna este monumento patrio, y lo hacía a través de la desfiguración de su superficie material, intentando eliminar su integridad prístina a través de rayados, vestiduras, disfraces, inscripciones. Una acción popular que, a ojos de la institucionalidad, ya no parece ser tan inocente, puesto que ha insistido en develar, en diversas capas, lenguajes y corporalidades, que lo que ese monumento encarna es una memoria condenable a la luz de las demandas políticas, sociales y económicas desenterradas en octubre del año 2019. Es posible pensar que ese vínculo, el linaje, ha sido fracturado. En su lugar, se exacerba la imagen de la toma de conciencia, que se expresa en el borramiento de la imagen reluciente del monumento, reinscrito a través de una trama que expresa, en sus inscripciones, el drama social y el grito por una sociedad más justa, equitativa y digna.

Baquedano se ha convertido, en términos de Whelan (2002), en un "lienzo sobre el que se expresa [una] lucha de poder (...) [siendo] una fuente importante para desentrañar las geografías de cambios políticos y culturales más amplios" (Whelan 2002, p.508). Y 
con ello, la antes valorada como inocente acción popular, constitutiva del patrimonio, que permitía valorar su dinamismo y disonancia como principios rectores de una noción que se autoproclamaba crítica y actualizada, se vuelve una amenaza, porque, precisamente, lo que esa acción popular desafía es la integridad material que resguarda y pone en tensión aquellos principios canónicos de la ideología canónica patrimonializante. Durante meses, bajo las luces de la madrugada, el monumento fue repuesto a su imagen original; fue sucesivamente higienizado y pintado, mientras que de día era permanentemente custodiado por un cerco policial, el cual, disuelto por grupos calificados por los medios y la autoridad como subalternos y vándalos, arremetía porfiadamente para tomarse nuevamente el lugar. Hasta entonces, esta disputa por el monumento permitía, también, inocentemente, preguntarnos si podía el monumento destruido ser reconocido en su valor patrimonial e histórico o, si acaso, podía la estatua reapropiada y resignificada formar parte del patrimonio cultural institucionalmente establecido. Y en este punto de conflicto, ante la mirada atenta de la ciudadanía, se decidió retirar el monumento antes de un inminente final en lo que pareció la crónica de una muerte anunciada (Imagen 1).

5 Antes de cualquier otra intervención en el monumento, se expulsó toda posibilidad de una nueva destrucción. El lugar de memoria fue reemplazado por un espacio vacío protegido por un gran muro de metal, de casi tres metros de altura (Imágenes 2 y 3), que en un perímetro cuadrado custodia con afán marcial lo que subyace anónimamente bajo el plinto: el monumento ausente (Márquez y Hoppe, 2021); el monumento al soldado desconocido. ¿Es la tumba desconocida lo resguardado afanosamente por la guardia policial o es la perpetuación de una disputa de poder por el control, aún sin Baquedano, de la huella latente que deja su partida? ¿Tendrá la movilización y representación en la figura pétrea una carga política aurática tan poderosa que exige, pese a su ausencia, la protección del espacio desmonumentalizado y el resguardo de aquella base que sobrevive al sacrilegio que, a ojos de las fuerzas militares, la ciudadanía ha efectuado en su contra? Sea cual sea la clave para comprender la erección de ese gran muro metálico, lo cierto es que evoca una imagen bélica, guiño a un muro de Berlín o a los muros transfronterizos en zonas de conflicto migratorio.

6 De pie desde la vereda de enfrente, la visión de la base del monumento ausente (incluso podríamos decir del monumento secuestrado) nos impide ver lo que hay tras esas placas de metal. Solo es posible observar la plaza desgastada cubierta de polvo. Y quizás ya no sea tan amenazante la presencia militar como esa gran muralla que blinda el acceso, visión y contemplación de uno de los espacios patrimoniales más emblemáticos de nuestra ciudad. En efecto, ese muro metálico corrompe toda posibilidad de interacción y apropiación del patrimonio. Estamos antes una lógica de blindamiento del patrimonio; un muro que ciega la visión del lugar, que lo cubre, tapa y protege de toda acción popular que provenga del exterior. Un patrimonio blindado que protege y escuda al espacio desmonumentalizado de todo golpe externo, como si ese muro estuviese levantado para resistir los efectos de balas y el fuego del paisaje exterior. En contraposición a lo dicho por Salvatore Settis, el patrimonio blindado no es ni público ni agente de acción popular; sino que, por el contrario, es privado y despojado de toda posibilidad de encuentro gestual, político y cultural. ¿Cómo entender la decisión de blindar el patrimonio cuando precisamente lo que enuncia su principio es la naturaleza cambiante, viva y disonante? ¿Cómo entender el sentido de construcción y apropiación del patrimonio en nuestras ciudades, cuando el gesto de blindaje ciega y niega toda posibilidad de interacción y ocupación de los monumentos que dicen ser de todos y 
todas, pero que en el fondo no pueden tocarse ni mirarse? ¿Será que más que patrimonio colectivo e histórico estamos en presencia de un patrimonio militar que evidencia la latente presencia del poder marcial en el seno de nuestra sociedad?

7 Lo cierto, es que la insistente defensa militar y política del monumento Baquedano ante su iterativa intención de desmonumentalización, el posterior retiro de la estatua y la inmortalización de su protección del lugar con el levantamiento de ese gran muro de metal, nos recuerda la historia del patrimonio y los temores y resistencias que le habitan siempre en pulsión de su conservación material. Aunque hoy el discurso en torno al patrimonio y los monumentos se construyan con idearios disonantes y complejos, la operación conservacionista opera bajo claves jurídicas, éticas y morales que terminan trayendo a la memoria, en su sentido más clásico, que los monumentos deben cuidarse, protegerse, evitar los sacrilegios en su contra, salvaguardarlos a como dé lugar, controlar su culto y promover la empatía por ellos. Si esta certeza se rompe, si la acción popular embate contra esta integridad y los monumentos son efectivamente usados y apropiados, si se constituyen en lugares de una memoria reivindicativa y reparatoria, acaece la privación sensorial en el espacio y esterilidad táctil (Sennet, 1994) mediante la prohibición de observar, acceder, tocar y usar. Así, a condición de perpetuar su materialidad en el tiempo para legarlo a la memoria de las futuras generaciones, el gran muro que blinda el monumento vuelve este bien público o bien de uso de espacio público y común, en un bien privado de las fuerzas del orden, el cual cercado con paneles de metal encarna una de las mayores contradicciones del patrimonio; los idearios de transformación, transmisión, apropiación y conmemoración versus las prácticas de prohibición, desuso y control.

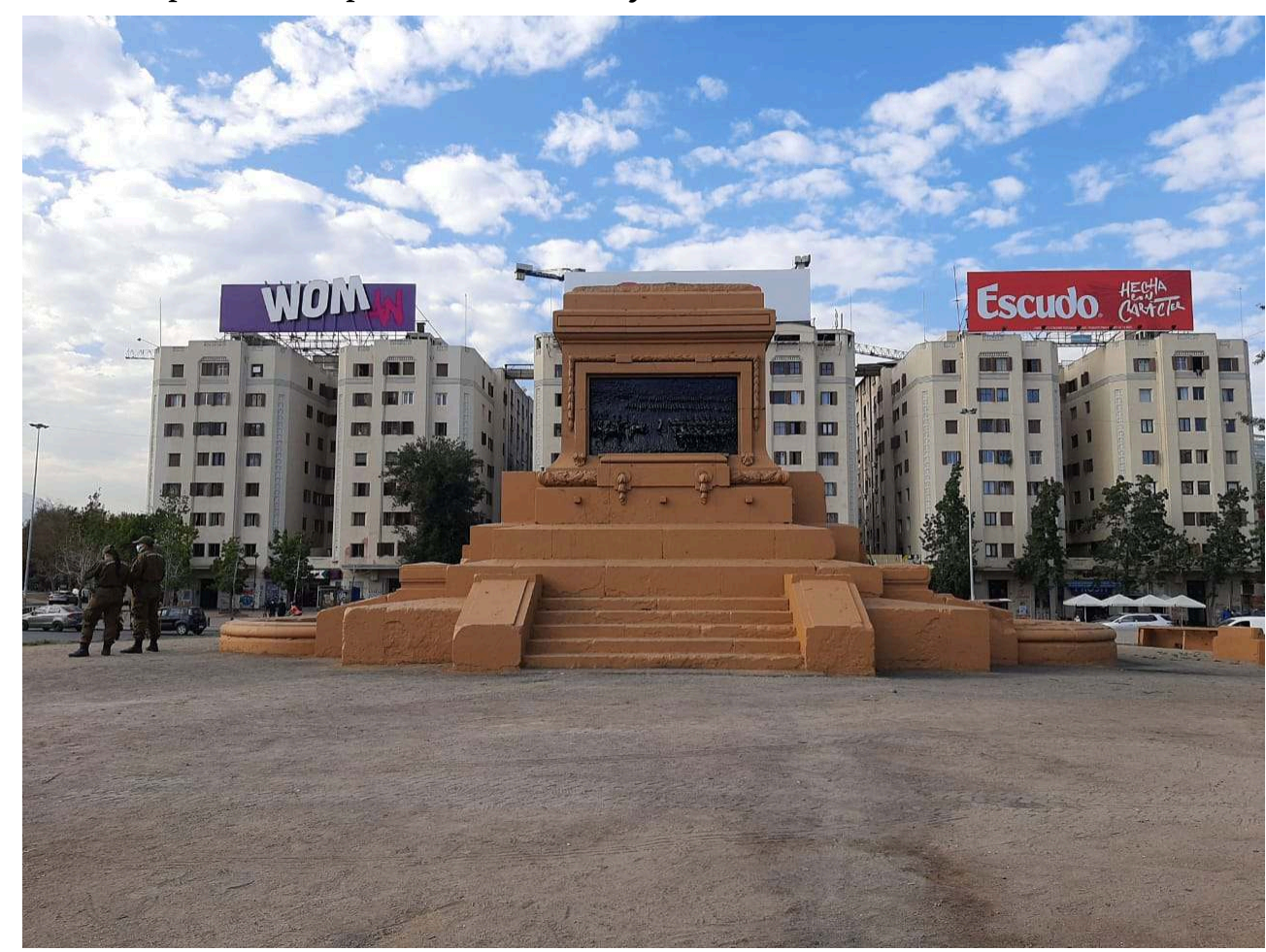

IMAGEN 1. Plinto del monumento al general Baquedano tras el retiro de la estatua; Santiago. Foto: Alvaro Hoppe, Fondecyt 1180352, 2021. 


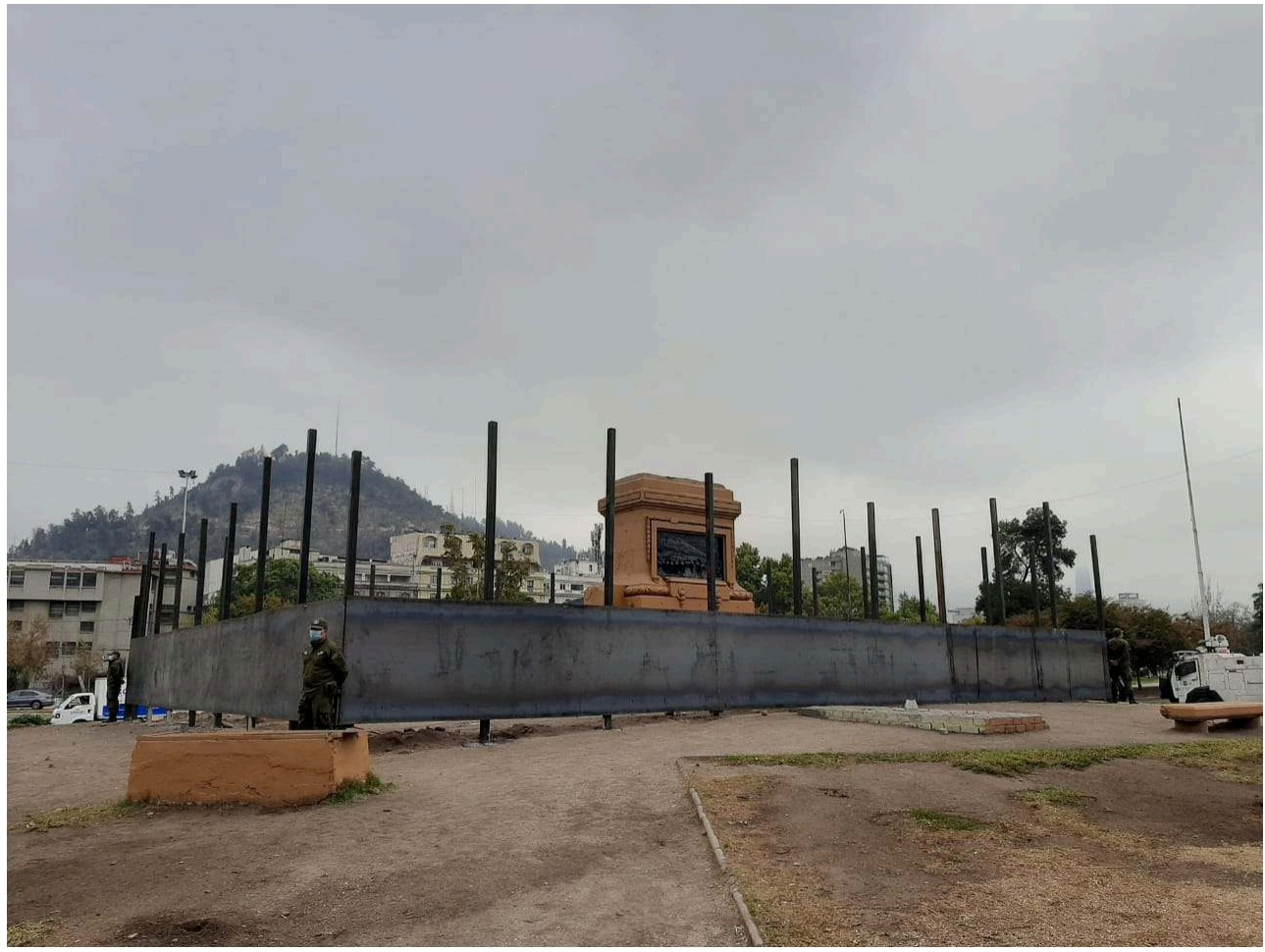

IMAGEN 2. Muro que blinda el plinto del monumento al general Baquedano. Foto: Alvaro Hoppe, Fondecyt 1180352, 2021.

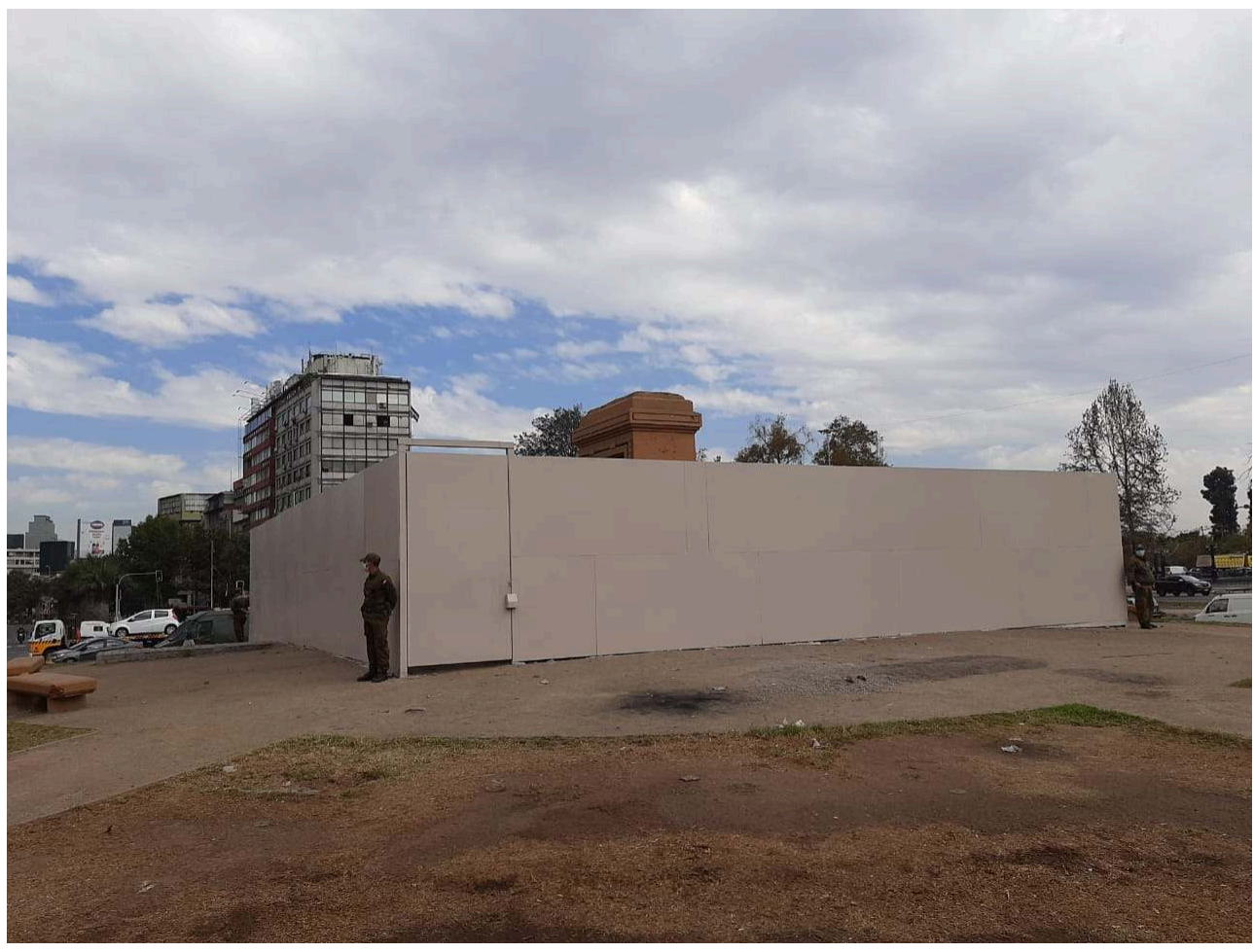

IMAGEN 3. Muro que blinda el plinto del monumento al general Baquedano. Fuente: Alvaro Hoppe, Fondecyt 1180352, 2021. 


\section{BIBLIOGRAPHY}

Chababo, R. (2017). La piedra y el fusil. Rosario: Casa Grande.

Lukinovic, J. (2021). La guerra de los monumentos. Santiago: Camino.

Márquez, F. y Hoppe, A. (2021). El monumento ausente. Le Monde diplomatique, 15, (Recuperado de https://www.lemondediplomatique.cl/el-monumento-ausente-por-francisca-marquezantropologa-y-alvaro-hoppe-fotografo.html)

Sennet, R. (1994). Carne y piedra. El cuerpo y la ciudad en la civilización occidental. Madrid: Alianza.

Whelan, Y. (2002). The construction and destruction of a colonial landscape: Monuments to British monarchs in Dublin before and after Independence. Journal of Historical Geography, XXVIII(4), 508-533. https://doi.org/10.1006/jhge.2002.0441

FUENTES

Bustamante, J. (2021) Notas de campo. Relato de feriantes en una feria de Santiago. Santiago de Chile.

\section{AUTHOR}

\section{JAVIERA BUSTAMANTE DANILO}

Universidad Alberto Hurtado, Chile.

Correo electrónico: bustamante.javiera@gmail.com 